Int. J. Electrochem. Sci., 15 (2020) 1437 - 1449

\title{
2-(3H-Imidazol-4-yl)-ethylamine as a Green Corrosion Inhibitor for Q235 Steel in Hydrochloric Acid
}

\author{
Jinliang Zhang \\ School of Materials and Chemical Engineering, Ningbo University Of Technology, Ningbo, \\ Zhejiang 315211, China \\ E-mail: zhangjinliang_nut@163.com
}

doi: $10.20964 / 2020.02 .27$

Received: 8 September 2019 / Accepted: 25 October 2019 / Published: 31 December 2019

2-(3H-Imidazol-4-yl)-ethylamine (HIE) was researched as a green novel corrosion inhibitor for Q235 steel in $1 \mathrm{M} \mathrm{HCl}$. In this work, electrochemical methods, surface morphology analysis, and theoretical calculations were used to explore the corrosion inhibition performance of HIE. Electrochemical results show that HIE can exhibit superior anti-corrosion performance for Q235 steel in HCl. SEM and AFM intuitively prove that HIE can effectively inhibit the corrosion of Q235 steel. In addition, it is worth mentioning that the adsorption of HIE on the Q235 steel surface is consistent with Langmuir isotherm adsorption. The quantum chemical calculations and molecular dynamics simulations had demonstrated that HIE exhibits excellent corrosion inhibition performance.

Keywords: 2-(3H-Imidazol-4-yl)-ethylamine; Q235 steel; hydrochloric acid; corrosion inhibitor; Langmuir isotherm adsorption; molecular dynamics simulations

\section{FULL TEXT}

(C) 2020 The Authors. Published by ESG (www.electrochemsci.org). This article is an open access article distributed under the terms and conditions of the Creative Commons Attribution license (http://creativecommons.org/licenses/by/4.0/). 